\title{
Some sources of error in British occupational mortality data
}

\author{
M. R. ALDERSON ${ }^{1}$ \\ Faculty of Medicine, Southampton University
}

\begin{abstract}
Alderson, M. R. (1972). Brit. J. industr. Med., 29, 245-254. Some sources of error in British occupational mortality data. Shortly after the Registrar General (1855) produced the first tables of occupational mortality there were doubts about the accuracy of this material. This paper reviews the development of the decennial reports on occupational mortality and the attempts that have been made to improve the quality of the analyses. Information on a representative sample of deaths among men aged 20 to 64 dying in Bristol during 1962/63 is reported. Occupational histories were obtained for $591(85 \%)$ of the subjects in the sample and were coded. These codings are compared with the coding of the occupations recorded at death registration.

Comparison of the occupation recorded at death registration and the final occupation from the interview indicated that there was complete agreement for $79 \%$ of subjects; there were negligible discrepancies for $6 \%$, minor discrepancies for $5 \%$, and major discrepancies for $10 \%$.

Forty-one percent of the subjects were known to have had two occupations, and $13 \%$ of the subjects three or more. The occupation recorded at death registration was compared with the principal occupation recorded at interview. Complete agreement was found for $58 \%$ of the subjects, and the proportion of major differences rose to $28 \%$. Most of these differences between the two sets of data were due to a reported change in occupation during the working life of the men in the study. It was not possible to tell if this switch from one occupation to another was a result of the onset of the disease. A number of authors have drawn attention to the fact that the onset of occupationally induced disease may be associated with declining work capacity and that this can result in an individual changing his job. Because the occupational mortality rates published by the Registrar General relate to the final occupation recorded at death registration, occupationally induced disease associated with changes in occupation will not show up in these rates. A number of ways of overcoming this difficul ty are discussed; a chronological occupational history might be obtained either at death registration or by linking the occupations of an individual recorded at successive censuses. It might then be possible to calculate mortality rates by principal occupation. This would add considerably to the burden of data collection and processing, and there is no clear evidence that the rates so obtained could justify the additional effort. It is suggested that occupational mortality data, as published by the Registrar General, are extremely useful as a background to the study and understanding of occupational disease and mortality; despite doubts about the accuracy of the material, the study supports the continued production of this supplement following each decennial census.
\end{abstract}

${ }^{1}$ The author has been greatly assisted by Dr. A. Adelstein and Mr. F. Rooke-Matthews, Office of Population Censuses and Surveys. 
Hardly had the Registrar General (1855) produced the first tables of occupational mortality than doubts were raised about the accuracy of this material. This paper reviews the development of the decennial occupational mortality reports, the published discussions about their accuracy, and the attempts made to improve the quality of the analyses. A comparison is presented between occupation recorded at death notification and a chronological occupational history obtained by an interviewer for a representative sample of adult male deaths while co-operating in the Inter-American Investigation of Mortality. ${ }^{1}$ The value of occupational mortality data is examined in the light of these findings, and various ways of changing the data collection and analysis are discussed.

\section{Background}

Hunter (1959) records that Ramazzini wrote in the eighteenth century about disease occurring in over 60 occupations. Increasing attention was paid to the effect of occupation on health in the early part of the nineteenth century. In 1832 Thackrah published his work 'The Effects of Arts, Trades and Professions on Health and Longevity'. Chadwick's (1842) 'Report on the Sanitary Condition of the Labouring Population of Great Britain' stressed the need for the collection and examination of facts. A few years later Engels (1845) wrote 'The Condition of the Working Class in England'. Farr (1875) pointed out that all previous writers employed methods which could render no precise results except in cases where the influences they dealt with were very powerful.

It was a major advance when the Registrar General (1855) collated information from the 1851 census and the mortality returns for that year. He wrote 'The previous investigations of the various rates of mortality in the districts of the Kingdom have shown how much the health and life of the population are affected by fixed local influence. The professions and occupations of men open a new field of enquiry, on which we are now prepared to enter, not unconscious, however, of peculiar difficulties that beset all enquiries into the mortality of limited, fluctuating, and sometimes ill-defined sections of the population. Attention was drawn to the inaccuracy of the classification of occupations and the need to study age-specific mortality rates rather than crude rates when comparing the health

${ }^{1}$ The Inter-American Investigation of Mortality is a research project of the Pan American Health Organisation made possible by Research Grant GM-08682 of the National Institute of General Medical Sciences of the U.S. Public Health Service and by co-operation and support of Ministries of Health, local health authorities, and schools of medicine and public health in the 12 cities. of men in different occupations. In the Supplement to the 25th Annual Report of the Registrar General, Farr (1864) discussed briefly the data obtained at the time of the 1861 census and suggested that the mortality of men in unhealthy occupations might be reduced by the investigation and removal of its cause. The first detailed analysis of the problems involved in the interpretation of occupational mortality data was by Ogle (1885) in his letter to the Registrar General included in the Supplement to the 45th Annual Report (1885). He gave a clear description of the selection processes into and out of occupations and concluded that after the fullest weight had been allowed for all the defects, 'there can be no reasonable doubt but that the death rates do furnish valuable indications of the comparative salubrity of different industrial occupations'. Earlier reports had been based upon deaths occurring in a one- or two-year period; this Supplement indicated that the accuracy of the rates had been increased by the use of three years' deaths in the numerator. For the first time death rates were provided by cause, injury, and 20-year age groups.

Much more specific information was provided in the Supplement to the 55th Annual Report of the Registrar General (1897). This was partly by the use of a finer classification of occupation but also because population data by occupation had been abstracted from the 1891 census material by 10 -year age groups. In his letter to the Registrar General in this Supplement, Tatham described the work entailed in the production of deaths tabulated by 24 causes, 100 occupations, and 10-year age groups. In an article contributed to a book on dangerous trades Tatham (1902) provided a very clear exposition on the selection into and out of occupations, pointing out how the effect of the demands of the job may restrict entry to those of above average physique while failing strength may force a man to relinquish his job. He eloquently described the sad lot of one compelled to change through a series of posts from skilled worker to cab-driver to street hawker until unemployed. Because of these difficulties he acknowledged that mortality can be regarded at best as only a rough measure of the healthfulness of an industry and that registration of sickness was required to measure the damage done by several industries to the health of workers.

Whereas previous reports had been based on figures for occupied males the Supplement to the 65th Annual Report of the Registrar General (1908) combined the statistics for the retired and for those still occupied at death. Tatham pointed out that retired applied to those who, by reason of success, had retired in comfort, and also those who, by permanent breakdown in health (perhaps caused by stress of employment), had been deprived of the ability to earn a living. It was felt that the figures 
based only upon occupied men could not accurately measure total loss for a given occupation.

Stevenson, in the 74th Annual Report of the Registrar General (1913), described how the births and deaths of infants had been used to calculate the infant mortality rates by occupation of the father. The data were also consolidated by summing the occupations into a number of groups designed to represent as far as possible different social grades. This is often referred to as the initial production of mortality data by social class, but it is worth noting that Farr (1864) had grouped the occupational orders into five classes-professional, domestic, commercial, agricultural and industrial.

The Supplement to the 75th Annual Report of the Registrar General Part IV (1919) was produced after considerable delay due to the first world war. It contained a series of tables of mortality by social class, age, and cause, and again provided a good discussion of the reservations involved in the interpretation of occupational mortality statistics. It was pointed out that mortality may be unconnected with a man's occupation; determined by general conditions of life implied by the occupation; or directly due to an occupational risk. The deficiencies in the classification caused specific hazards, such as are known to occur to lead glaze workers, to be lost as such individuals are grouped with all those engaged in pottery manufacture. A further source of error was discussed by Collis and Greenwood (1921); they pointed out that selective weeding out of the unfit affected certain occupations very much and all to some extent. They suggested that this could be overcome only if the life histories of all citizens were recorded and changes in their occupations returned to the General Register Office.

A new classification of occupations was introduced in the Registrar General's Decennial Supplement for 1921 (1927); the primary axis of classification became occupational rather than industrial. This helped to identify specific groups of process workers with defined risk. In the report for 1910-12, cutlery grinders were included in the general group Cutler and Scissor Maker with a mortality raised by $63 \%$; in the 1921-23 data grinders of cutlery are a separate group with mortality raised by $230 \%$.

In the Registrar General's Decennial Supplement for 1931 (1938), mortality rates for married women were produced for the first time. This had been suggested in the previous report as a means of differentiating direct occupational risk to males and the risk from general conditions of life. Another method of assisting with the interpretation of the material was suggested by Reid (1954); he showed how self selection in and out of occupations may be studied by the comparison of age-specific mortality rates for 10-year periods over the total working span. He also drew attention to the 'promotion' that may occur in quoting the occupation, both self promotion at the census and, more particularly, by the widow motivated with pride or charity at death registration. No specific evidence was advanced to support this contention.

A comprehensive discussion of the inaccuracies of the data and the measures taken to obviate these was provided in the Registrar General's Decennial Supplement for 1951 (1958). For the first time the rates were based on deaths for a five-year period around the census, which increased the accuracy of the rates for small occupational groups though a problem still remained for the examination of uncommon causes of deaths occurring among small groups of workers. It was felt that minor errors were introduced by the fact that the census was not held exactly at the mid-point of the central years for deaths, and that slight changes might occur in occupation between the census and the time of death. Minor mis-statements of occupation may occur at census and death registration: it was thought that this would balance out in the total data, and that the quite different circumstances of census reporting and death registration were of more serious consequence.

The error introduced into the mortality rates due to men over 60 recording themselves as unoccupied on census schedules but being recorded as retired at death registration had been discussed in the Registrar General's Decennial Supplement for 1931 (1938). This matter is again dealt with in the 1951 Supplement (1958), which pointed out that the proportion of men recorded at the census as 'having no gainful occupation' was much higher for those aged 65 and over than for younger men. The majority of these should have been recorded as retired, the occupation before retirement being given. This led to an error in the denominator for occupied or retired males of $7 \%$ in the age group $65-69$ and $13 \%$ in the age group $70+$. More use was, therefore, advocated of the age-specific data and the standardized mortality ratio for persons aged 20 to 64 . The 1951 Supplement also mentioned the differences in intake into various occupations and the varying drop-out rate from occupations because of illness. It was felt that switching from job to job, for reasons other than sickness, may be self-cancelling.

One specific study has been carried out which provides some data relevant to a discussion of the accuracy of mortality data. Heasman, Liddell, and Reid (1958) reported a survey of the accuracy of job descriptions on records used for the calculation of indices of occupational mortality and morbidity in the mining industry. These authors comment on errors in the description of occupations used in the numerator and denominator of the occupational mortality rates. They do not discuss the problem of correctly assessing the health hazards in those 
migrating from one occupation to another because of industrial disease.

No report on occupational mortality has yet been published in the 1961 census series ${ }^{1}$, but the General Report of the census published by the General Register Office (1968) contained particulars of two studies of the quality of the basic data. Following the 1961 census a post-enumeration survey was carried out for the first time, to check the accuracy of the information collected at the census. Some of the occupation questions were differently phrased and comparisons between the census and the postenumeration survey are difficult to interpret, though it did confirm overstatement of the number economically inactive.

The second study discussed in the Report of the Census concerned the matching, for a sample of deaths occurring shortly after the census, of the death registration and the census schedule. Data have been published for 2196 men. Of these, $1390(63 \%)$ were assigned to the same occupation unit at death registration and at the census; 225 $(10 \%)$ were assigned to different units within the same occupation order while $581(27 \%)$ were assigned to different orders. On detailed study of 99 discrepancies, 35 were pairs of records for quite different jobs with no apparent connexion; for 27 the men had been assigned at the census to order XXVIII (inadequately described occupation); 16 pairs apparently referred to the same job but differed by only the details specified; while for 16 pairs the jobs recorded were different, but related and in the same industry. One death registration quoted two occupations, twice the census schedule quoted a part-time occupation, and there were two coding errors. In addition a contingency table was provided for social class derived from the census data and from the death register for 2250 men; the totals for the five social classes derived from either source were similar due to compensating errors in the allocation of individuals.

Despite the above series of qualifications about the interpretation of occupational mortality rates, four authors have recently suggested that the published data are of value. Benjamin (1968) discussed the errors inherent in the occupational mortality data and concluded that they can establish a prima facie case for detailed study. Schilling (1960) pointed out the inability of the national rates to identify hazards of small groups of workers exposed to specific chemical hazards (and the problems of disease causing prolonged morbidity but negligible mortality). Nevertheless, he concluded that the Registrar General brings new occupational risks to

'The Registrar General's Decennial Supplement on Occupational Mortality for England and Wales for 1959-63 was published in 1971, after this article had been accepted for publication. our notice and reminds us of old ones still present. McKeown and Lowe (1966) reiterated the difficulties in interpreting occupational mortality rates but concluded that the data have many uses. They suggested that there is value in the comparison of general mortality and cause specific mortality between occupations, and the comparison of one occupation with the national average.

\section{Present investigation}

Detailed occupational histories were collected for a representative sample of deaths in Bristol from 1962 to 1964 . The chronological histories permitted examination of the changes in occupation occurring during the working life of each of the subjects; if an individual had changed his job a number of times an assessment has been made of the alteration in health risk associated with each change of job. The effect of minor variations in the job description on the coding of the occupation has been examined, and also the frequency with which change of status is reported during working life. This information has been compared with the occupation given at the time of death registration.

\section{Method}

Three-quarters of the deaths occurring among adult residents of Bristol aged 15 to 74 were entered into the sample. This was obtained by listing three out of four death notifications in the order in which they were completed by the Registrar. This report relates to data collected in the first year of the study, 1 October 1962 to 30 September 1963.

The method has been described in detail by Puffer and Griffith (1967), but brief particulars are given here. The recording of occupational histories was governed by the protocol for the investigation as a whole. All women were excluded from the analysis. The Registrar General (1958) has shown so clearly the need to restrict consideration of occupational mortality to those aged 20 to 64 that the results now reported are for men aged 20 to 64 .

A health visitor visited the next of kin about four to six weeks after each death. These visits were restricted to relatives resident within the city boundary; if difficulty was found in contacting a relative an attempt was made to obtain information from a close friend of the deceased. Three visits at varying times of the day were made before giving up an attempt to obtain particulars. An occupational history was obtained, starting with the job first held on leaving school; particulars were recorded about each subsequent job. The respondent was asked to describe the status of the individual, the actual occupation involved, and the industry within which the occupation was performed. In addition the actua! wording of the occupation quoted by the informant at the time of death registration was transcribed onto the questionnaire. If an individual changed jobs but continued in the same occupation and industry and his status did not change, a separate entry was not made and the total time in the occupation was recorded. Details of the death registration were passed to the General 
Register Officer to assist identification in their records. The staff of this office abstracted the code allocated to the occupation recorded by the registrar and in addition coded each occupation recorded by the interviewer, according to the Classification of Occupations, 1960. A three-digit occupation code was provided together with a fourth-digit status code. For each record in the sample comparison has been made between each of the occupations recorded in the detailed histories and the occupation given at death registration using the actual wording given for the occupations and the codes allotted. Each comparison was allocated to one of four categories according to the following definitions:

\section{Major discrepancy}

The wording of the two sets of data was such that the occupations have been coded to different Orders in the Classification of Occupations and subjective judgement indicated that the codes were consonant with quite different potential risks to health.

\section{Minor discrepancy}

The wording of the two sets of data was such that the occupations have been coded to different occupation Units within the same Order while subjective judgement indicated that the general risks to health were usually the same.

\section{Negligible discrepancy}

The wording of the two sets of data was such that the occupations have been coded to the same three-digit unit code but differ in the status digit.

\section{Agreement}

The wording of the two sets of data was such that the occupations have been coded to the same three-digit occupational code and the same status code.

\section{Results}

There were 693 deaths among the men aged 20 to 64 entered into the study, but it was found impossible to obtain an occupation history for $102(15 \%)$ of these subjects; there remained 591 records.

The simplest comparison is between the inforformation obtained at death registration and the final full-time occupation given at interview (Table 1). Twenty-three of the 28 minor discrepancies were due to differences in the wording given in the two sets of data. For example, a man was recorded as foreman fitter at interview and machine shop foreman at death registration; it was thought that these represented alternative descriptions for the same job. Of the 62 major discrepancies, 20 were also due to variation in the wording used to describe the final job; for example, a man was recorded as clerk for bookseller at interview but bookseller's warehouseman at death registration. Eight major discrepancies arose because a previous occupation had been recorded at death registration. There were 20 major discrepancies associated with differences in 'implied social standing'; for example, one man was
TABLE 1

Comparison of Occupation Recorded at Death Registration and Final OcCupation Recorded AT INTERVIEW FOR 591 DEATHS OF MEN AGED 20 Tо 64

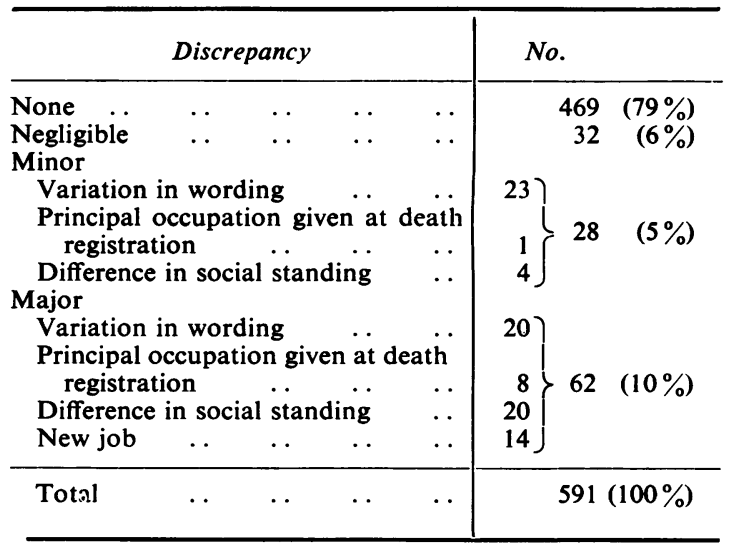

recorded as labourer at smelting works at interview, but process worker at smelting works at death registration. The remaining 14 major discrepancies were due to an occupation being recorded at death registration which bore no resemblance to any of the information given at interview. For example, a 57-year-old man was recorded as having been a coal miner for 20 years in South Wales, he then moved to Bristol and was said to have been a labourer at the aircraft factory for three years, and finally a warehouse porter at a cold storage; at death registration he was recorded as canteen worker.

A comparison has been made of the principal occupation recorded at interview (i.e., the occupation that the deceased had pursued for the longest period) with the occupation recorded at death registration (which should be the occupation held at the time of death or, for retired persons, the last full-time occupation) (Table 2). The number of negligible and minor discrepancies is slightly greater than in the previous table. An example is a 38-year-old man who had worked for 14 years as a builder's labourer and then for 10 years until his death as a mill hand; he was quite correctly recorded as mill hand at death registration, which is a minor discrepancy with his principal occupation. The number of major discrepancies is considerably higher in this second comparison, reflecting the changes that can occur in a man's career. An example of this was a 55-year-old man who had been a chimney sweep for 35 years, first as an employee for 17 years, then self-employed for a further 18 years; he had been a barman for a year. Finally he had worked as a nursing assistant for three years.

A more detailed examination has been made of 
TABLE 2

Comparison of Occupation Recorded at Death Registration with Principal Occupation RECORDED AT INTERVIEW FOR 591 DEATHS OF MEN AGED 20 TO 64

\begin{tabular}{|c|c|c|c|c|c|c|c|}
\hline \multicolumn{5}{|c|}{ Discrepancy } & \multicolumn{3}{|c|}{ No. } \\
\hline \multicolumn{5}{|c|}{ 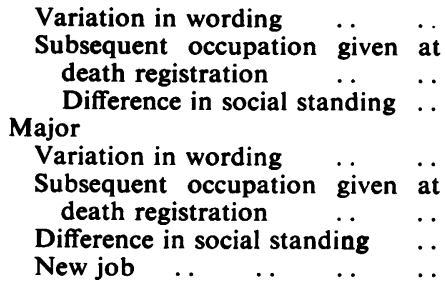 } & \multicolumn{3}{|c|}{$\left.\begin{array}{r}345 \\
42 \\
22 \\
16 \\
4\end{array}\right\} \begin{array}{ll}(58 \%) \\
42\end{array}$} \\
\hline Total & $\cdots$ & $\ldots$ & $\ldots$ & $\ldots$ & & 591 & $(100 \%)$ \\
\hline
\end{tabular}

the data where there is a discrepancy between the final occupation recorded at interview and that recorded at death registration, due to either difference in status or differences in the social standing implicit in the wording of the occupation. The simplest discrepancies are those where the occupational code is identical but the status code differs; there were 32 such cases (Table 1, negligible discrepancy). Some were due to the addition of foreman, charge hand, or master to the stated occupation; the remainder were due to differences in the way shop assistant/shop manager/shop owner were recorded. On 27 occasions the status was elevated at death registration, and depressed in five (considering the status scale to run from employee, foreman, self-employed without employees, to self-employed with employees). In five subjects the information at death registration would have elevated the social class and made no change to the remaining 27 subjects. There were four minor discrepancies accompanied by change in social standing; in all, the information at death registration had implied a senior and more skilled manual post. There were 20 major discrepancies associated with change in social standing; in four of these, a less skilled post had been implied while the remaining 16 had been coded from information at death registration to more skilled or more responsible posts.

It has been pointed out that onset of ill health can be associated with change in occupation, but occupational mortality rates published by the Registrar General relate to terminal occupation. Occupationally induced disease causing change in occupation will not be identified in the published data, and therefore the material reported here has been examined to show factors associated with change in occupation. It had not proved possible to obtain a complete record back to the first job held after leaving school in $129(22 \%)$ of those interviewed. For those with one job specified, $27 \%$ had the initial job recorded as unknown, with two jobs specified $20 \%$ had initial job unknown, and with three or more jobs specified $10 \%$ had the initial job recorded as unknown. This trend is very unlikely to be a chance finding ( $\chi^{2}$ test for trend $=11 \cdot 2$; D.F. $=2 ; P<0.005$ ).

One hundred and twenty-nine $(22 \%)$ of the men had served in the armed Forces at the time of either the first or second world war. Table 3 shows the distribution of men by the number of $(a)$ civilian occupations recorded, (b) civilian occupations recorded including 'initial unknown' as an additional job, (c) counting service in the armed Forces as a further occupation. There was no evidence that previous service in the armed Forces was linked to premature retirement, or age at death in this sample. Twenty-six percent of those holding one civilian job had been in the army, $25 \%$ of those holding two jobs, and $9 \%$ of those holding three or more civilian jobs. This finding is very highly significant $\left(\chi^{2}=15.9\right.$; D.F. $=2 ; \mathrm{P}<0.0005$ ).

A higher proportion of men was recorded as being retired among those who had held one or two different jobs compared with those recording three or four, though this did not reach the $5 \%$ level of significance. However, when this was examined within age groups, $28 \%$ of those aged 55 to 64 who had held only one or two jobs were retired, while $15 \%$ were retired among those who had held three or four jobs. This difference is unlikely to be due to chance $\left(\chi^{2}=4.8 ; \quad\right.$ D.F. $\left.=1 ; \quad P<0.05\right)$. Some occupations provide security of tenure, and a reduced pension may be taken on retirement before the age of 65. A few individuals hold jobs with such financial

\section{TABLE 3}

Distribution of Men by (a) Number of Civilian OCCupations Recorded, $(b)$ Civilian OCCuPation Plus 'Unknown Initial Job, (c) Civilian plus UnKNown plus SERVICE IN ARMed ForCes

\begin{tabular}{c|rr|rr|rr}
\hline \multirow{2}{*}{$\begin{array}{c}\text { No. of } \\
\text { occupations }\end{array}$} & \multicolumn{4}{|c|}{ Occupation } \\
\cline { 2 - 7 } & Civilian & \multicolumn{3}{|c|}{$\begin{array}{c}\text { Civilian }+ \\
\text { initial unknown }\end{array}$} & \multicolumn{2}{c}{$\begin{array}{c}\text { Civilian }+ \\
\text { initial unknown } \\
+ \text { armed Forces }\end{array}$} \\
\cline { 2 - 7 } & No. & $\%$ & No. & $\%$ & No. & $\%$ \\
\hline 1 & 273 & 46 & 199 & 34 & 148 & 25 \\
2 & 240 & 41 & 267 & 45 & 251 & 43 \\
3 & 77 & 13 & 116 & 20 & 172 & 29 \\
4 & 1 & 0 & 9 & 1 & 20 & 3 \\
\hline
\end{tabular}


returns that premature retirement can be chosen without financial embarrassment. Inspection of the occupational histories suggested that such factors played a negligible part in determining premature retirement in this sample of men.

There appeared to be an association between age at death and number of occupations held. Thirtyseven percent of those having held one job were under 55 at death compared with $34 \%$ of those having two jobs and only $26 \%$ of those who had three occupations; the trend is not significant at the $5 \%$ level $\left(\chi^{2}\right.$ for trend $=2.62 ;$ D.F. $\left.=1 ; \mathrm{P}<0.20\right)$.

Table 4 compares the proportion of occupations (a) recorded on the 1961 census schedules, (b) recorded at interviews in Bristol, 1962-63, that agree with the occupations recorded at death registration or differ at Unit and Order level. The proportion of Unit and Order differences is very much lower for the Bristol data $\left(\chi^{2}=98.7\right.$; D.F. $=2$; $\left.P \ll 0.0001\right)$.

\section{TABLE 4}

Proportion of OCCUPATIONS ReCORded (a) ON Census SCHedules IN 1962, $(b)$ AT INTERVIEW IN BRISTOL 1962-63 THAT AGREE OR DIFFER AT UNIT OR ORDER LEVEL WHEN COMPARED WITH FINAL OcCupation Recorded at Death Registration

Comparison between two sets of data

\begin{tabular}{cc|cccr}
\hline \multicolumn{1}{c|}{ Source } & Agree & $\begin{array}{c}\text { Unit } \\
\text { difference }\end{array}$ & $\begin{array}{c}\text { Order } \\
\text { difference }\end{array}$ & \multicolumn{1}{c}{$\begin{array}{c}\text { No. of } \\
\text { deaths }\end{array}$} \\
\hline Census &. & $63 \%$ & $10 \%$ & $27 \%$ & $2196(100 \%)$ \\
Bristol &. & $85 \%$ & $5 \%$ & $10 \%$ & $591(100 \%)$ \\
\hline
\end{tabular}

$x^{2}=98.7$; D.F. $=2 ; \mathrm{P}<<0.001$.

\section{Discussion}

It was not possible to obtain a chronological occupational history for $15 \%$ of the men aged 20 to 64 . Generally this was because there was no next of kin resident in Bristol. Occasionally no relative could be traced, even after three visits to the last known address. The degree of bias introduced into the comparison between the two sources of data is difficult to estimate.

The data are not necessarily representative of the national picture, particularly when one considers the chronological work histories. Bristol had a range of mixed industry (manufacture of tobacco products, food and other commodities, paint, chemicals, clothing, footwear, aircraft engines, other machinery); the type and diversity of industry to a certain extent cushioned Bristol against the worst problems of the economic depression in the 1930s (Little, 1954).
The comparisons between the occupations obtained by the interviewer and the registrar are presented as two sets of data, and there is no proof that when a discrepancy is reported the information provided and recorded is the correct version, but the time available to the interviewer enabled her to probe more deeply to elicit reliable responses, while the collection of chronological histories may have lessened the tendency for status inflation to occur.

The percentage of Unit and Order differences between the final occupation from interview and the death registration data reported here are very significantly $(P<0.0001)$ lower than those recorded from the 1961 post-census check between occupation on census schedule and at death notification. This suggests that some of the differences in the latter comparison were due to the recording of incorrect information on the census schedule rather than at death notification. Unfortunately, information was not available about the proportion of deaths in which the informant at death registration was (a) the person interviewed or (b) the person who completed the census schedule.

Numerous authors from Ogle (1885) onwards have discussed the selection out of occupations. It seems reasonable to assume, where an occupied male is affected by a chronic condition leading to gradually increasing incapacity with spells of sickness absence, that change from a heavy to a lighter job may occur. If the condition in question (e.g., chronic obstructive airways disease, ischaemic heart disease) was of occupational origin, this fact will be 'lost' in the mortality statistics due to the change of job. Should the individual be affected by a more rapidly progressive disease such as a malignancy, he may pass from the stage of initial symptoms to incapacity for work and then death without changing job; if the malignancy is due to carcinogens in the work environment the mortality statistics may give a lead to this providing (a) the worker has not changed his occupation during the long latent period of the disease; $(b)$ the specific work process involves sufficient men for the group to be tabulated on their own and not merged in with other workers; and (c) the malignancy involved is of the less common variety, so that the relative risk is greatly increased for those involved in the process in question. Because of the importance of this problem in the interpretation of occupational mortality, the change in occupation has been examined in the Bristol data. The Principal Occupation obtained by the interviewer agreed with that recorded by the registrar for $58 \%$ of the deaths in the sample. The discrepancies were due chiefly to the degree of changing of occupation among the men during their working lives. Fifty-four per cent were known to have had more than one job; when one includes 
those men for whom the respondent had not been able to provide information about the first job, the proportion pursuing two or more occupations rises to $66 \%$. A number of analyses are reported of the association of change of occupation with other factors; these are somewhat limited as they are derived from data collected for another purpose. In a planned study it would have been useful to record whether an individual changed his job owing to ill health and retired prematurely owing to ill health. Relevant information may be hard to obtain because of the difficulty in disentangling premature ageing, non-occupational chronic degenerative disease, and occupationally induced disease. In the data there was a suggestion $(P<0.20)$ that men dying at older ages had had more jobs; there was no suggestion that army service was associated with an alteration in the number of civilian jobs held; men who retired before death had held fewer jobs, this association being significant $(P<0.05)$ for men aged 55 to 64. This did not appear to be related to the availability of pension rights for premature retirement or earning capacity in the principal occupation; the data are compatible with the hypothesis that some men may switch to an easier job with advancing age, while others may be unable to do so and retire prematurely. An extension of this is the tentative suggestion that occupational mortality rates for men retired under the age of 65 may be a better reflection of occupational hazards causing chronic disease than death rates for occupied males (who may have switched to lighter work).

The data presented here on social class suggest that spurious increase in social class, because the informant enhances the description of the deceased's occupation, is a comparatively minor problem. The 'promotion' that Reid (1954), McKeown and Lowe (1966), and Benjamin (1968) refer to may be a theoretical rather than practical error in the statistics.

Over the past 100 years it has been suggested on a number of occasions that the occupational mortality statistics will 'throw up' fresh leads to industrial hazards, which will then warrant detailed. ad hoc study. However, a search of the literature and discussion with colleagues failed to identify a single major hazard that has been discovered where the initial hunch for the enquiry was derived from a study of published occupational mortality data. Scott (1967) reviewed recent advances in occupational medicine and suggested that today the doctor in industry should not have to depend on the appearance of gross disease or poisoning to show that a hazard exists. Clayson (1970) wrote that industrial cancers will come to light as a result of astute clinical observation; such reports then must be confirmed by systematic epidemiological surveys. No great support is thus provided for the continued use of mortality data to reveal previously unsuspected hazards.

A rather different use of mortality requires consideration - the help it provides in putting a specific problem in perspective. Lee (1969) has discussed the use made of occupational mortality data in the report on the health and safety of persons employed in metalliferous mines in the last century. Farr (1864) contributed evidence to the commissioners and provided special tabulations of the death rates among Cornish miners; this helped in the definition of the hazards involved. Occupational mortality data have been referred to, as background information, in a number of studies published in the last 10 years: mortality of miners and ex-miners in the Rhondda Fach (Cochrane, Carpenter, Moore, and Thomas, 1964); mortality of coal miners (Goldman, 1965); mortality of gas workers (Doll et al., 1965); mortality of trawler fishermen (Schilling, 1966); nasal cancer in the boot and shoe industry (Acheson, Cowdell, and Jolles, 1970); and mortality in haematite miners (Boyd, Doll, Faulds, and Leiper, 1970). Over the same period other studies have been published without any reference to use of the Registrar General's occupational mortality data: bladder cancer in cable workers (Davies, 1965); nasal cancer in woodworkers (Macbeth, 1965; Acheson, Hadfield, and Macbeth, 1967); mortality in asbestos factory workers (Newhouse, 1969). There is no evidence in any of the above studies that the initial hunch stemmed from careful scrutiny of the decennial supplements.

In the light of the above it is appropriate to consider whether modifications should be made to the current system. A number of alternative courses of action are open, though some may be discounted on grounds of cost. First, has a case been made out for continuation of the decennial supplements on occupational mortality even without drastic modification? Even if no major changes can be made in the system to improve the accuracy and relevance of the data, continuation is justified on the grounds of the background information that the reports provide. Their use in this respect is rather intangible and difficult to quantify, but a gap in our knowledge exists where a supplement has failed to appear (i.e., 1941 and 1961).

One source of error in the data is the use of different sources of information (census and death registration) to provide the numerator and denominator for the rates. The census schedule is basically a self completion form filled in by the head of the household under guidance from the enumerator. The informant at death registration may be a different person, questioned directly by the experienced registrar in very different circumstances. It is not self evident which method provides more accurate information; minor error may be introduced by 
either method. A man may also change his occupation between census night and date of death. Further study is required to explore the possibility of using samples of death notifications linked with census schedules; this might be done to identify discrepancy between the two sources of occupational data in order to institute a system of amendment. This approach might improve the accuracy of the rates, but the improvement in accuracy might not justify the expense; the rates would still be subject to the deficiency that they would be basically mortality by terminal occupation, unless the interval between census and matching with deaths increased markedly from several to many years. The chronological histories reported in this study indicate the extra dimension given to the data by this method; the registrars could be instructed to obtain a chronological history. This would require fresh legislation, which could be contemplated only if there was firm evidence that additional imposition on the work of the registrar and on the burden of the already distressed informant was justified. There is the added major complication, with a chronological history, of the derivation of an appropriate denominator. Further studies of this problem are required. Identifying men in different occupational groups at a census and linking them, after a lengthy interval, with the alphabetical register of deaths now being accumulated at the Office of Population Censuses and Surveys is theoretically feasible, and not really a new idea, having been suggested in outline by Collis and Greenwood (1921). The calculation of mortality rates by cause in cohorts of men from different occupations might compete with clinical skill and serendipity in defining new hazards, particularly where considerable shift in job occurs between exposure to risk and development of disease.

Apart from fatal accidents at work, other occupational risks will usually involve men in illness before death; some hazards will cause prolonged illness and low mortality and it is therefore important not to neglect the collation of morbidity statistics. Lee (1969) draws attention to an early use of these in 1864, while Tatham (1902) argued for their development. A number of industries have carefully monitored the sickness experience of their workers, and the Ministry of Pensions and National Insurance (1965) carried out a special inquiry in 1961/62 in which data on sickness absence were linked to occupational data for the population at risk.

I am most grateful to Professor R. C. Wofinden, Medical Officer of Health for Bristol, for inviting me to participate in this investigation. This study could not have been carried out without the co-operation of the relatives of the deceased, who were interviewed by Miss F. Chamberlain. The Registrar General's staff in the
Office of Population Censuses and Surveys kindly coded the occupations recorded in the study. Dr. P. Dixon assisted with the preparation of the data; Professor W. R. Lee and Dr. M. Newhouse read a draft of the report and both made most helpful suggestions.

\section{References}

Acheson, E. D. Cowdell, R. H., and Jolles, B. (1970). Nasal cancer in the Northamptonshire boot and shoe industry. Brit. med.J., 1, 385-393.

__ Hadfield, E. H., and Macbeth, R. G. (1967) Carcinoma of the nasal cavity and accessory sinuses in woodworkers. Lancet, 1, 311-312.

Benjamin, B. (1968). Health and Vital Statistics, p. 132. Allen and Unwin, London.

Boyd, J. T., Doll, R., Faulds, J. S., and Leiper, J. (1970). Cancer of the lung in iron ore (haematite) miners Brit. J. industr. Med., 27, 97-105.

Chadwick, E. (1842). The Sanitary Condition of the Labouring Population of Great Britain. Edinburgh University Press, 1965.

Clayson, D. B. (1970). Chemicals as carcinogens in man. Yorkshire Faculty J., 10, no. 2 (May) pp. 33-37.

Cochrane, A. L., Carpenter, R. G., Moore, F., and Thomas, J. (1964). The mortality of miners and ex-miners in the Rhondda Fach. Brit. $J$ industr. Med., 21, 38-45.

Collis, E. L., and Greenwood, M. (1921). The Health of the Industrial Worker, pp. 72-73. Churchill, London.

Davies, J. M. (1965). Bladder tumours in the electric-cable industry. Lancet, 2, 143-146.

Doll, R., Fisher, R. E. W., Gammon, E. J., Gunn, W., Hughes, G. O., Tyrer, F. H., and Wilson, W. (1965). Mortality of gasworkers with special reference to cancers of lung and bladder, chronic bronchitis, and pneumoconiosis. Brit. J. industr. Med., 22, 1-12.

Engels, F. (1845). The Condition of the Working Class in England. Reissued by Panther, London, 1969.

Farr, W. (1864). Supplement to the 25th Annual Report of the Registrar General, p. 440. H.M.S.O., London.

(1875). Supplement to the 35th Annual Report of the Registrar General, p. 1ii. H.M.S.O., London.

General Register Office (1968). Census 1961-Great BritainGeneral Report. H.M.S.O., London.

Goldman, K. P. (1965). Mortality of coal miners from carcinoma of the lung. Brit J. industr. Med., 22, 72-77.

Heasman, M. A., Liddell, F. D. K., and Reid, D. D. (1958). The accuracy of occupational vital statistics. Brit. J. industr. Med., 15, 141-146.

Hunter, D. (1959). Health in Industry, p. 36. Penguin, London.

Lee, W. R. (1969). Occupational medicine. In Medicine and Science in the 1860 s, edited by F. N. L. Poynter, pp. 151181. Wellcome Institute, London.

Little, B. (1954). The City and County of Bristol, p. 76. Warner Laurie, London.

Macbeth, R. (1965). Malignant disease of the paranasal sinuses. J. Laryng., 79, 592-612.

McKeown, T., and Lowe, C. R. (1966). An Introduction to Social Medicine, p. 53. Blackwell, Oxford.

Ministry of Pensions and National Insurance (1965). Report on an Enquiry into the Incidence of Incapazity for Work. H.M.S.O., London.

Newhouse, M. L. (1969). A study of the mortality of workers in an asbestos factory. Brit. J. industr. Med., 26, 294-301.

Ogle, W. (1885). In Supplement to the 45th Annual Report of the Registrar General, p. xxiv. H.M.S.O., London.

Puffer, R. R., and Griffith, G. W. (1967). Patterns of Urban Mortality, p. 12. Scientific Publication, No. 151, Pan American Health Organisation, Washington. 
Registrar-General (1855). 14th Annual Report of the Registrar-General of Births, Deaths, and Marriages in England. H.M.S.O., London.

(1864) Supplement to the 25th Annual Report. H.M.S.O., London.

(1885). Supplement to the 45th Annual Report. H.M.S.O., London.

(1897). Supplement to the 55th Annual Report of the Registrar-General, Part II. H.M.S.O., London.

(1908). Supplement to the 65th Annual Report of the Registrar-General, Part II. H.M.S.O., London.

(1913). 74th Annual Report of the Registrar-General of Births, Deaths, and Marriages in England and Wales. H.M.S.O., London.

(1919). Supplement to the 75th Annual Report of the Registrar-General, Part IV. H.M.S.O., London.

(1927). The Registrar-General's Decennial Supplement, England and Wales, 1921, Part II. Occupational Mortality, Fertility and Infant Mortality. H.M.S.O.

(1938). The Registrar-General's Decennial Supplement, England and Wales, 1931, Part IIa. Occupational Mortality. H.M.S.O., London.
(1958). The Registrar-General's Decennial Supplement, England and Wales, 1951, Occupational Mortality, Part II, vol. 1. H.M.S.O., London.

Reid, D. D. (1954). Statistical and epidemiological methods in occupational health. In Industrial Medicine and Hygiene, vol. 1, pp. 58-87, edited by E. R. A. Merewether. Butterworth, London.

Schilling, R. S. F. (1960). The measurement of health. In Modern Trends in Occupational Health, p. 2, edited by R. S. F. Schilling, Butterworth, London.

(1966). Trawler fishing: an extreme occupation. Proc. roy. Soc. Med., 59, 405-410.

Scott, T. S. (1967). Industrial medicine-an art or a science? Brit. J. industr. Med., 24, 85-92.

Tatham, J. (1902). Mortality of occupations. In Dangerous Trades, p. 121, edited by T. Oliver. Murray, London.

Thackrah, C. T. (1832). The Effects of Arts, Trades, and Professions, and Longevity on Health, 2nd ed. Longman, Rees, Orme, Brown, Green, and Longman, London. Reprinted Livingstone, Edinburgh. 1957.

Received for publication July 20, 1971. 